\title{
COVID-19; Perú a los 100 días, breve observación de una pandemia que pone en serios aprietos a la salud pública mundial
}

\section{COVID-19; Peru at 100 days, brief observation of a pandemic that puts world public health in serious trouble}

\section{Señor Editor:}

En diciembre de 2019 se identificaron en Wuhan (China) una serie de casos de neumonía originados por un nuevo coronavirus. Este nuevo coronavirus tiene distintas denominaciones: 2019-nCoV según la OMS y SARS-CoV-2 según el Comité Internacional de Taxonomia de Virus (1). Para el 11 de marzo de 2020, la Organización Mundial de la Salud (OMS) declaró la enfermedad COVID-19, causada por el nuevo coronavirus SARS-CoV-2, como una pandemia (2). Siendo hasta el día de hoy el evento más grande de la historia contemporánea que ha puesto en seria dificultad a la humidad entera por los estragos tanto en los sistemas de salud como en las cadenas productivas, comerciales y financieras de la economía mundial. Esta carta desea exponer de manera breve la cronología de la pandemia en el Perú (3), a los 100 días de haber iniciado la misma, haciendo una comparación con lo ocurrido en España (4).

En el grafico 1 se presenta un resumen de los poco más de 100 días que los peruanos convivimos con el COVID-19, comparándolo con lo ocurrido en

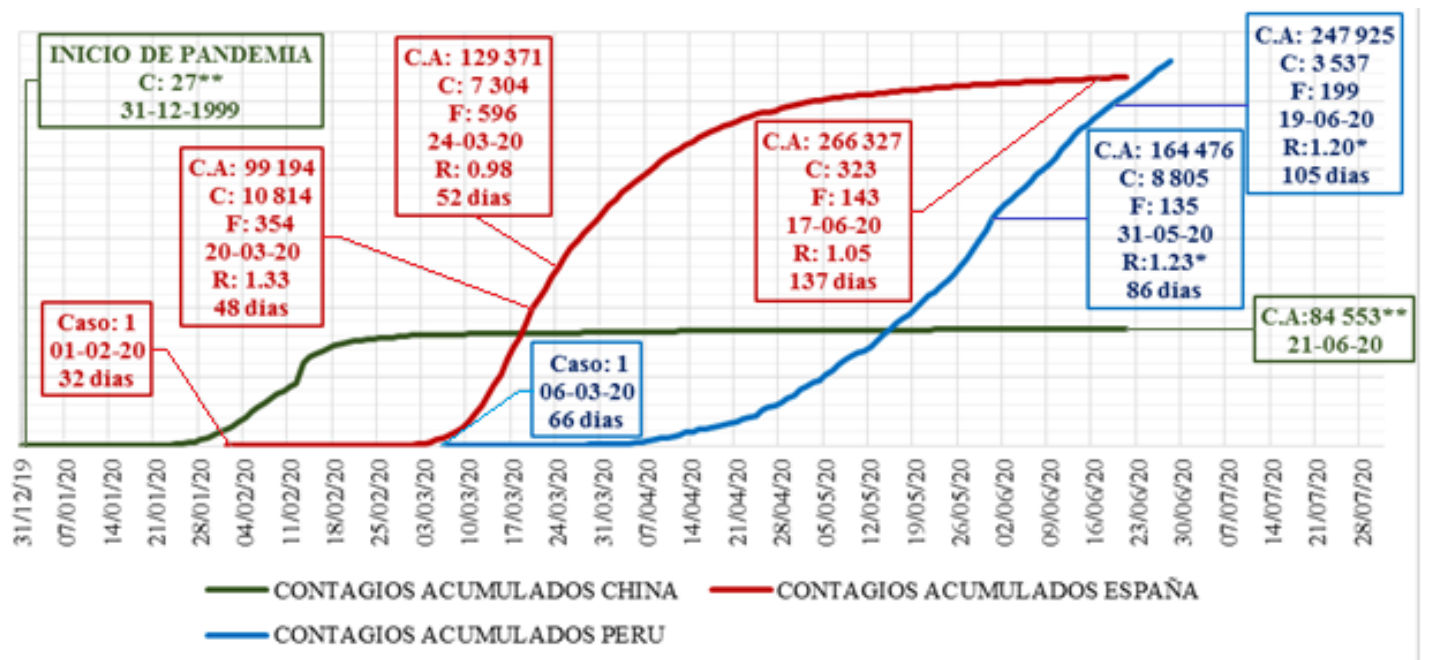

Gráfico 1. Cronología comparativa para evaluar los 100 días del Covid-19 en el Perú:

$$
\text { *(5); ** (6). }
$$

1 Departamento de Epidemiologia y Estadística del Cáncer, Instituto Nacional de Enfermedades Neoplásicas. Lima, Perú.

2 Registro de Cáncer de Lima, Instituto Nacional de Enfermedades Neoplásicas. Lima, Perú.

a Economista;

b Asistente estadístico;

c Licenciado estadístico;

d Obstetra;

e Asistente de investigación, 


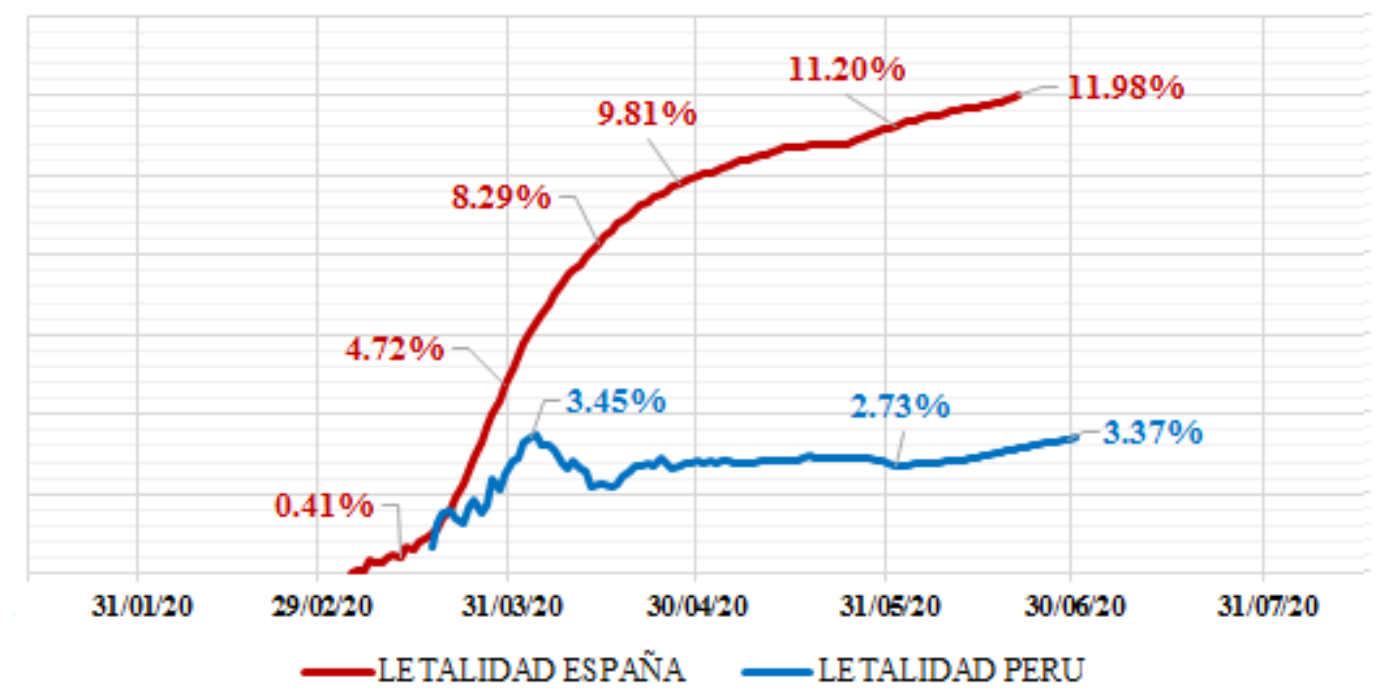

Gráfico 2. Curvas de Letalidad; España al 21-06-20 y Perú al 29-06-20.

España y lo sucedido en China, debemos de indicar la relatividad de las cifras, pues todas están en constante revisión y critica por los diferentes organismos de salud pública; El Perú tuvo 66 días de información o preparación antes que el virus debute estadísticamente y 86 días en alcanzar el número de máximo contagio, se puede decir también que a 105 días aún mantiene un $\mathrm{R}$ mayor a 1; entendiendo el $\mathrm{R}$ como el número de reproducción de una enfermedad infecciosa. A diferencia de España, 32 días de inter pandemia, 48 días en llegar al máximo número de contagios y 52 días en lograr un $\mathrm{R}$ menor a 1, desacelerando el contagio, y registrándose un repunte a los 137 días, con un $\mathrm{R}=1,05$; por el contrario, China lo tendría controlado en poco tiempo, en el grafico 2 se muestran unas curvas de letalidad bastante diferenciadas entre Perú y España.

Al sistema de salud peruano se le puede considerar precario e insuficiente; saber que solo contábamos con 100 camas UCI concentradas en su mayoría en la capital, donde habita el tercio de la población, nos da precisamente ese indicador, frente a las nueve mil camas UCI de España al inicio del proceso pandémico, señal de por si preocupante. Cien días después Perú alcanzó algo más de 1000 camas, con un 35,42\% de casos activos que requieren hospitalización; se podría decir, que las medidas de contención y mitigación de alguna manera ganaron tiempo para ir contrarrestando la demanda sanitaria de una pandemia de rápido contagio. A finales de junio, poco más de cumplir los 100 días, se decide levantar la cuarentena porque Lima registra un $\mathrm{R}$ menor a 1, manteniendo las restricciones focalizadas en Arequipa, Ica, Junín, Huánuco, San
Martín, Madre de Dios y Áncash.

Finalmente queda el reto de cambios estructurales en el sistema de salud público peruano, en medio de una pandemia que no da tregua y que demanda el concurso inmediato de todos, al obligarnos a entender los cambios drásticos y urgentes que nos serviría para poder convivir con una pandemia que promete quedarse.

Enrique Zevallos-Santillan 1,a; 2,b, José Cruzado-Burga ${ }^{1, b, c}$, Ruth Avalos-Rivera ${ }^{1, d ; 2, e}$.

\section{Correspondencia:}

Enrique Zevallos Santillán

Correo electrónico: ezevallo@hotmail.com

\section{REFERENCIAS BIBLIOGRÁFICAS}

1. Palacios Cruz M, Santos E, Velázquez Cervantes MA, León Juárez M. COVID-19, una emergencia de salud pública mundial. Rev Clin Esp. 2020 Mar 20:S00142565(20)30092-8. English, Spanish. doi: 10.1016/j. rce.2020.03.001. Epub ahead of print. PMID: 32204922 ; PMCID: PMC7102523.

2. Buss P M, Tobar S. La COVID-19 y las oportunidades de cooperación internacional en salud. Cadernos de Saúde Pública. 2020; 36(4): e00066920. Doi: https:// doi.org/10.1590/0102-311X00066920

3. Universidad Nacional de Ingeniería. Covid19-Perú. Lima: Universidad Nacional de Ingeniería; 2020. (Citado el 2 de julio del 2020) Disponible en: https:// covid19.orcebot.com/

4. Instituto de Salud Carlos III. COVID-19.Madrid: 
Centro Nacional de Epidemiologia; 2020. (Citado el 2 de julio del 2020) Disponible en: https:// cnecovid.isciii.es/covid19/\#ccaa

5. La Republica data. Tasa de contagio de COVID-19 por región en Perú. Lima: La Republica data; 2020. (Citado el 2 de julio del 2020) Disponible en: https:// data.larepublica.pe/envivo/1551044-numero-rregiones-covid19
6. European Centre for Disease Prevention and Control. Download today's data on the geographic distribution of COVID-19 cases worldwide. Estocolmo: European Centre for Disease Prevention and Control; 2020. (Citado el 2 de julio del 2020) Disponible en: https:// www.ecdc.europa.eu/en/publications-data/ download-todays-data-geographic-distributioncovid-19-cases-worldwide

Recibido: 03/07/2020

Aceptado: 06/08/2020 